\title{
Metabolismo urbano e gestão de resíduos sólidos: um diálogo necessário à gestão de cidades
}

Urban metabolism and solid waste management: a needed dialogue to cities management

Metabolismo urbano y gestión de residuos sólidos: un diálogo necesario para la gestión de las ciudades

Recebido: 01/03/2021 | Revisado: 06/03/2021 | Aceito: 20/01/2022 | Publicado: 21/01/2022

\author{
Rafaela Cajado Magalhaes \\ ORCID: https://orcid.org/0000-0003-4619-9556 \\ Universidade Estadual do Ceará, Brasil \\ E-mail: rafaela.cajado0105@gmail.com \\ Ana Cristina Batista dos Santos \\ ORCID: https://orcid.org/0000-0001-8838-6937 \\ Universidade Estadual do Ceará, Brasil \\ E-mail: ana.batista@uece.br \\ Brenno Buarque \\ ORCID: https://orcid.org/0000-0001-6656-9759 \\ Universidade Estadual do Ceará, Brasil \\ E-mail: brenno_buarque@hotmail.com \\ Herus Orsano Machado \\ ORCID: https://orcid.org/0000-0001-6383-6102 \\ Universidade Estadual do Ceará, Brasil \\ E-mail: herus.machado@ifma.edu.br \\ Hermano José Batista de Carvalho \\ ORCID: https://orcid.org/0000-0003-0910-2356 \\ Universidade Estadual do Ceará, Brasil \\ E-mail: hermano.carvalho@uece.br
}

\section{Resumo}

Este trabalho foi desenvolvido com o objetivo de compreender a influência do conceito de Metabolismo Urbano (MU) nas estratégias utilizadas para a gestão de resíduos sólidos em duas cidades da Região Metropolitana de uma capital do nordeste brasileiro. A metodologia utilizada foi de cunho qualitativo, por meio da análise de conteúdo de 4 entrevistas individuais realizadas em profundidade. $\mathrm{Na}$ análise dos resultados, verificou-se que a influência do conceito de MU nas estratégias utilizadas para a gestão de resíduos sólidos nas cidades estudadas é mínima ou ausente, visto que, os gestores públicos envolvidos estão alheios, ou pouco sabem a respeito do conceito em estudo, demonstrando, portanto, uma visão reducionista da gestão de resíduos sólidos. Assim, limitam suas práticas ao serviço de coleta e disposição final de resíduos sólidos.

Palavras-chave: Fluxo de materiais e energia; Gestão socioambiental; Gestão pública.

\begin{abstract}
This study was conducted in order to understand the influence of the concept of urban metabolism (MU) in the strategies used for solid waste management in two cities in the metropolitan region of a northeastern Brazil capital. The methodology used was a qualitative nature, by means of four individual interviews conducted in-depth analysis of content. In analyzing the results, it was found that the influence of the concept of MU the strategies used for the management of solid waste in the cities studied is minimal or absent, since the public officials involved are unrelated, or know little about the concept study, demonstrating therefore a reductionist view of solid waste management. Thus, they limit their practices to the collection service and final disposal of solid waste.
\end{abstract}

Keywords: Flow of materials and energy; Socio-environmental management; Public management.

\section{Resumen}

Este trabajo fue desarrollado con el objetivo de comprender la influencia del concepto de Metabolismo Urbano (MU) en las estrategias utilizadas para la gestión de residuos sólidos en dos ciudades de la Región Metropolitana de una capital del noreste de Brasil. La metodología utilizada fue de carácter cualitativo, mediante el análisis de contenido de 4 entrevistas individuales realizadas en profundidad. En el análisis de los resultados, se encontró que la influencia del concepto de UM en las estrategias utilizadas para el manejo de residuos sólidos en las ciudades estudiadas es mínima o nula, ya que los gestores públicos involucrados desconocen o saben poco sobre la concepto en cuestión estudio, 
demostrando, por tanto, una visión reduccionista de la gestión de residuos sólidos. Así, limitan sus prácticas al servicio de recolección y disposición final de residuos sólidos.

Palabras clave: Flujo de materiales y energía; Gestión socioambiental; Gestión pública.

\section{Introdução}

Resíduos sólidos estão presentes desde os primórdios, sendo comumente denominados "lixo" (Andrade \& Ferreira, 2011). A vida em sociedade envolve consumo e descarte de produtos essenciais e supérfluos. O nível de consumo é influenciado por expansão urbana e avanço tecnológico, combinados ao crescimento populacional. O meio ambiente tem sofrido transformações e intervenções, associadas ao rápido ciclo inputs-outputs provenientes do consumo intensificado.

As discussões políticas sobre a gestão de resíduos sólidos como um dos grandes problemas de gerenciamento urbano foram intensificadas no início do século XX, quando as indústrias aumentavam suas produções, orientadas pela ascensão social, advinda da Revolução Industrial. Esse cenário foi relatado na Assembleia Geral da ONU, em 22 de dezembro de 1989 e resultou na criação da Resolução $n^{\circ}$ 44/228 que defende o desenvolvimento de estratégias para cessar ou reduzir os efeitos da degradação ambiental no mundo (Castro \& Araújo, 2004). Em 1992, na Conferência das Nações Unidas sobre o Meio Ambiente e o Desenvolvimento - ECO-92, durante as discussões da Agenda 21, foi definido que os problemas relacionados à gestão de resíduos sólidos deveriam ser fundamentados em quatro pontos, para o desenvolvimento de estratégias eficientes, sendo eles: a diminuição dos resíduos produzidos; a maximização da reutilização e reciclagem dos resíduos; a promoção da disposição e do tratamento; e a ampliação da cobertura no serviço de coleta de resíduos (Castro \& Araújo, 2004).

No Brasil, em 2010, o governo federal sancionou a Política Nacional de Resíduos Sólidos (PNRS) - Lei no 12.305, de 2010 -, tendo como finalidade disciplinar as diretrizes relativas ao gerenciamento de resíduos sólidos, considerando a gestão integrada como uma estratégia essencial. A PNRS também define as responsabilidades dos geradores de resíduos sólidos e a atuação do poder público frente aos instrumentos econômicos aplicáveis (Rocha et al., 2017). Na visão de alguns autores, a PNRS apresenta problemas para sua efetiva aplicação, destacam-se a baixa disponibilidade orçamentária e a fraca capacidade institucional e de gerenciamento de muitos municípios brasileiros, especialmente os de pequeno porte (Heber \& Silva, 2014). Para enfrentar esses desafios, essa lei estabelece diretrizes de gestão compartilhada, como a formação de consórcios intermunicipais de gerenciamento dos resíduos sólidos. (Maiello et al., 2018).

No que concerne à esfera ambiental, percebe-se uma lacuna de conhecimento a respeito da real extensão do impacto causado pelas atividades urbanas sobre os sistemas naturais (Kuhn et al., 2017). Nesse aspecto, destaca-se o alto nível de gravidade relacionado a dados como os da produção média de 80 mil toneladas diárias de resíduos sólidos, em 2015, no Brasil (Programa das Nações Unidas para o Desenvolvimento no Brasil [ONUBR], 2016). Conforme o Panorama dos Resíduos Sólidos no Brasil, realizado em 2016, 59,7\% dos municípios brasileiros destinam seus resíduos sólidos em locais impróprios (Associação Brasileira das Empresas de Limpeza Pública e Resíduos Especiais [ABRELPE], 2016).

Esta pesquisa aborda a problemática da gestão de resíduos nas cidades baseada na corrente teórica do Metabolismo Urbano (MU), que considera a análise da cidade como um organismo vivo, onde os fluxos de entrada e saída de materiais e energia associados às atividades de produção e consumo são sistemáticos, tornando-se necessário compreender o funcionamento desses fluxos para a adoção de um modelo de gestão adaptativa (Galvão et al., 2017).

A pesquisa foi norteada pela questão: qual a influência do conceito de MU nas estratégias de gestão de resíduos sólidos em cidades da Região Metropolitana de uma capital do nordeste brasileiro? Diante desse questionamento têm-se como objetivo compreender a influência do conceito de MU nas práticas de gestão de resíduos sólidos em cidades da Região Metropolitana de uma capital do nordeste brasileiro.

Este artigo está dividido em cinco seções, além desta introdução. Consecutivamente, a metodologia, onde se detalha a Abordagem e Tipologia da pesquisa, as Técnicas de Coleta e Análise de Dados e o Perfil do Objeto de Estudo. A literatura é 
revisada abordando-se duas temáticas: Gestão de Resíduos Sólidos e suas Políticas de Gestão; MU e a Análise dos Fluxos de Materiais (AFM). Os resultados da pesquisa de campo, analisados em: Práticas de Gestão de Resíduos Sólidos; Percepção dos Servidores sobre o Conceito de MU; Relação entre a Percepção de MU e Práticas de Gestão de Resíduos Sólidos. Por fim, as considerações finais dos autores.

\section{Metodologia}

\subsection{Abordagem e tipologia da pesquisa}

Diante das particularidades que envolvem os objetos estudados pela ciência social aplicada, a abordagem qualitativa refere-se a pesquisas que expõem uma realidade com base em elementos não quantificáveis (Minayo, 2002). Segundo Pereira A.S. et al. (2018, p.67) as pesquisas qualitativas "são aqueles nos quais é importante a interpretação por parte do pesquisador com suas opiniões sobre o fenômeno em estudo". O autor destaca ainda que a coleta de dados na maioria das vezes ocorre por meio de entrevistas com questões abertas. O presente estudo se caracterizou por uma abordagem qualitativa, pois trabalhou-se com a perspectiva de explorar através da fala dos entrevistados, variáveis não dimensionáveis, capazes de responder ao questionamento principal da pesquisa. Esta pesquisa foi do tipo exploratório-descritiva, visto que, teve como objetivo levantar dados e informações visando entender o contexto das estratégias de GRS nas cidades metropolitanas selecionadas para o estudo, a partir do conceito de MU. Pretendeu-se, também, descrever as práticas de GRS identificadas e analisar a relação entre a percepção do conceito de MU e as práticas atuantes.

\subsection{Técnicas de coleta e análise de dados}

O tipo de instrumento utilizado foi a entrevista semiestruturada "cujo sistema de coleta de dados consiste em informações diretamente do entrevistado" (Marconi \& Lakatos, 2010, p. 195). O roteiro de entrevista norteou a pesquisa com base nos seguintes tópicos-guia: i) dados de identificação do gestor; ii) questionamentos sobre a Secretaria em que o gestor entrevistado atuava no setor público; iii) perguntas relacionadas à GRS dos municípios em questão; iii) perguntas sobre o tema "MU", com o uso de uma foto figurativa e do termo em questão escrito em um papel, como elementos estímulo que, segundo Albandes-Moreira (2002), quando apresentados ao entrevistado atuam simultaneamente de forma ampla e focal como apoio no processo de entrevista; e iv) questionamentos que relacionaram a GRS e o tema "MU".

Figura 1. Foto Figurativa.

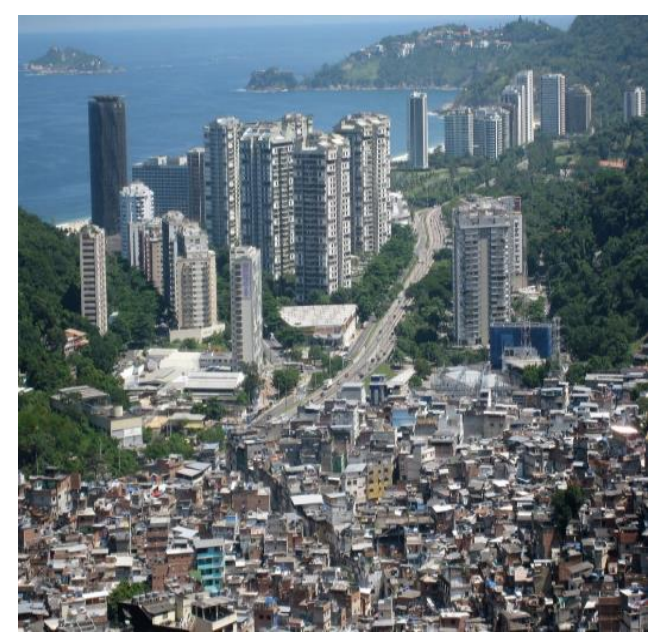

Fonte: Autores. 
Vale ressaltar que as entrevistas foram gravadas com o consentimento dos entrevistados, conforme termo de consentimento e confidencialidade, assegurando o sigilo de suas identificações.

Em relação à análise de resultados das entrevistas foi realizada a análise temática de conteúdo que, segundo Vergara (2005), defende a definição de categorias quanto ao propósito da pesquisa. Para a compreensão do contexto em que os dados coletados estão inseridos é necessária a realização das seguintes etapas: i) categorização do tema em estudo, com o uso de unidades de contexto; ii) o processo de inferência na pesquisa, com a identificação de núcleos de sentido necessários para a posterior classificação das unidades de contexto em temáticas; e iii) descrição e interpretação dos dados, que deve discutir o questionamento e os objetivos norteadores do estudo, em questão, com os temas advindos do campo (Gomes, 2002).

Nesta pesquisa, as categorias estão relacionadas aos temas que envolvem estratégias de GRS e a influência do conceito de MU nas mesmas, assim como, analisar, através das falas dos entrevistados a percepção dos mesmos em relação aos conceitos de MU e as práticas de GRS utilizadas, nas cidades metropolitanas G e P. Vale ressaltar que as quatro entrevistas realizadas foram transcritas, na íntegra, divididas em trechos e categorizadas a fim de garantir a fidelidade da análise de conteúdo das informações disponibilizadas pelos entrevistados.

\subsection{Perfil do objeto de estudo}

A presente pesquisa foi realizada em dois municípios da região metropolitana de uma capital do nordeste brasileiro, identificados na pesquisa pelas letras "G" e "P". A Região Metropolitana estudada é delimitada por uma área de $3.483 \mathrm{Km}^{2}$ (CPRM, 1998). O Estado em questão produz, em média, 9 mil toneladas por dia de resíduos sólidos (ALBREPE, 2016), o que ressalta a relevância deste estudo.

Deve-se enfatizar que para a realização dos estudos de campo foi pesquisado, previamente, a respeito das secretarias responsáveis pela GRS nos municípios selecionados para a pesquisa. A partir daí, verificou-se que o estudo de campo deveria abranger a Secretaria de Infraestrutura (G) e a Secretaria de Patrimônio, Serviços Públicos e Transportes (P), pois elas assumiam papéis estratégicos, onde atuavam de forma direta nas ações relacionadas a essa gestão.

A cidade "G" possui extensão territorial de 145, $1 \mathrm{Km}^{2}$ com o número de 72.299 habitantes, registrados pelo último censo (Instituto Brasileiro de Geografia e Estatística [IBGE], 2010). O município apresenta contínuo desenvolvimento econômico e comercial, demonstrado pelo Produto Interno Bruto registrado em R \$ 479.294.350. Este é composto por 16 secretarias, entre elas a secretaria de infraestrutura, responsável pela GRS do município. Além disso, sabe-se que a cidade produz em média 128,21 toneladas de lixo por dia (IBGE, 2010).

O município "P" possui extensão territorial de $1.293 \mathrm{~km}^{2}$ e um nível de urbanização de, aproximadamente, 89,18\%, correspondendo a um total de 290.220 moradores residindo em áreas urbanas do município (IBGE, 2010). Desse modo, é composto por 14 secretarias, entre elas a Secretaria de Patrimônio, Serviços Públicos e Transporte, responsável pela GRS do município. Além disso, sabe-se que a cidade produz em média 1.032,3 toneladas diárias de resíduos (IBGE, 2010), configurando o segundo município que apresenta maior índice de produção de resíduos do Estado.

Para atingir os objetivos da pesquisa foram realizadas entrevistas com quatro gestores públicos que atuavam, direta ou indiretamente, na GRS das cidades metropolitanas G e P. Os entrevistados foram selecionados para participar da pesquisa por atuarem em cargos relacionados às secretarias municipais responsáveis pela GRS de cada cidade e por possuírem conhecimento técnico e histórico, de forma que, pudessem responder às questões relacionadas às estratégias desenvolvidas para a GRS nas cidades em questão. O Quadro 1 mostra a caracterização dos entrevistados. 
Quadro 1 - Caracterização dos Entrevistados.

\begin{tabular}{|c|c|c|c|c|c|c|}
\hline Sujeito & Sexo & Idade & Escolaridade & Cargo/Função & $\begin{array}{l}\text { Tempo de } \\
\text { Gestão }\end{array}$ & Tempo no Cargo \\
\hline G1 & M & $\begin{array}{c}28 \\
\text { anos }\end{array}$ & Mestre & $\begin{array}{c}\text { Assessor técnico na autarquia } \\
\text { de meio ambiente }\end{array}$ & 7 anos & 2 anos \\
\hline G2 & M & $\begin{array}{c}57 \\
\text { anos }\end{array}$ & Especialista & Secretário de Infraestrutura & 1 ano e 10 meses & 1 ano e 2 meses \\
\hline P1 & M & $\begin{array}{c}62 \\
\text { anos }\end{array}$ & Graduado & $\begin{array}{c}\text { Secretário do Patrimônio, } \\
\text { Serviços Públicos e } \\
\text { Transportes } \\
\end{array}$ & 1 ano & 6 meses \\
\hline $\mathrm{P} 2$ & $\mathrm{~F}$ & $\begin{array}{c}24 \\
\text { anos }\end{array}$ & Especialista & $\begin{array}{c}\text { Gestora (Secretaria do } \\
\text { Patrimônio, Serviços Públicos } \\
\text { e Transportes) }\end{array}$ & 1 ano & 10 meses \\
\hline
\end{tabular}

Fonte: Autores.

\section{Gestão de resíduos sólidos (GRS) e suas políticas de gestão}

Resíduo sólido é conceituado como "todo e qualquer material sólido ou semi-sólido indesejável e que necessita ser removido por ter sido considerado inútil por quem o descarta, em qualquer recipiente destinado a esse ato" (Instituto Brasileiro de Administração Municipal [IBAM], 2001, p.25). Já para Demajorovic (1995), lixo e resíduos sólidos diferenciam-se conceitualmente. O primeiro não apresenta finalidades além do descarte; já o resíduo sólido apresenta valor econômico agregado, por estimular o reaproveitamento.

De acordo com o Banco Mundial, em 2016, a produção mundial de resíduos sólidos urbanos (RSU) atingiu, em média, 2,01 bilhões de toneladas. Os países desenvolvidos são responsáveis pela produção de, em média, 34\% dos resíduos do mundo, fato contrastante com o número de habitantes desses países, já que os mesmos representam, apenas, $16 \%$ da população mundial (ONUBR, 2016).

Segundo o relatório da ONU Meio Ambiente (2017), a produção diária de RSU nos países da América Latina e do Caribe, em 2017, atingiu, aproximadamente, 540 mil toneladas. Paralelamente, no Brasil, a quantidade de resíduos sólidos gerados foi de 78,4 milhões de toneladas, $91,2 \%$ desse montante foi coletado e 6,9 milhões de toneladas não foram direcionados a tratamento, resultando na destinação imprópria dos mesmos (ABRELPE, 2017).

Para De Andrade e Ferreira (2011) a gestão eficiente dos resíduos sólidos em uma cidade necessita que a coleta englobe mais de $90 \%$ da população continuamente, atingindo uma média de três vezes por semana; além de enfatizar a importância da limpeza pública para a manutenção satisfatória dos logradouros e o depósito dos resíduos em locais adequados, por exemplo em aterros sanitários.

No entanto, a visão de alguns autores contesta que a eficiência da gestão dos resíduos se resuma a coleta e disposição final dos mesmos, visto que, a quantidade de resíduos depositados tem atingido números assustadores, provocando grandes impactos ambientais e econômicos para as cidades, que investem muitos recursos na manutenção da coleta desses resíduos. Demajorovic (1995) defende que a Gestão de Resíduos Sólidos (GRS) deve priorizar um "ecological cycle management, ou seja, a montagem de um sistema circular, onde a quantidade de resíduos a serem reaproveitados, dentro do sistema produtivo, seja cada vez maior e a quantidade a ser disposta, menor" (p. 90). O autor ainda afirma que, ao invés de reciclar os resíduos gerados, é prioritário reutilizá-los, citando como fator importante o reaproveitamento da energia proveniente dos mesmos.

Os sistemas de GRS nos países apresentam variações que dependem de diversos fatores relacionados ao nível de desenvolvimento dos mesmos. Segundo Bruce (1995), as estratégias de GRS utilizadas pelos países desenvolvidos são pautadas em um sistema hierárquico de etapas que compreende a minimização, a reutilização, a reciclagem, a recuperação da energia proveniente do processo de incineração e a disposição final em aterros sanitários. O funcionamento desse sistema exige um alto nível de complexidade para as políticas de GRS nesses países. A temática da GRS, nos países centrais, foi 
regulamentada por uma Diretiva, criada em 1999, que envolveu regras para a atuação dos países nesse tipo de gestão, onde uma delas, referia-se a previsão de que, em 2014, a maioria dos resíduos fossem processados, através de unidades de tratamentos, antes da disposição final em aterros sanitários (Eigenheer, et al., 2005). Vários países desse bloco passaram a investir em medidas alternativas que reduzissem o custo no processo de tratamento dos resíduos gerados, entre eles, a Finlândia, onde $95 \%$ dos recipientes de bebidas são reutilizáveis, já a Dinamarca foi pioneira na proibição de comercialização de bebidas em recipientes não descartáveis (Miller Jr, 2007).

No Brasil, as políticas de GRS apresentam uma realidade divergente dos métodos utilizados nos países desenvolvidos. Apesar da produção de resíduos ser, relativamente, menor do que a produção nos países centrais, é notória a ineficiência nesse tipo de gestão, demonstrada através da visível precariedade da limpeza pública. Além disso, deve-se salientar a grande diferença entre as estruturas e metodologias utilizadas na limpeza pública de grandes centros urbanos e dos pequenos municípios brasileiros, caracterizada, principalmente, pela carência de unidades de tratamento dos resíduos nos municípios de pequeno porte (De Andrade \& Ferreira, 2011).

Em relação à disposição final, cerca de $59,01 \%$ ou 42,3 milhões de toneladas dos resíduos sólidos coletados são dispostos em aterros sanitários. Dos 5.565 municípios brasileiros, 3.352 municípios ainda despejam os resíduos coletados em locais inadequados, como lixões ou aterros controlados, que não possuem sistema de tratamento para a proteção do solo e do meio ambiente, totalizando uma porcentagem exorbitante de 40,9\% dos resíduos coletados. No tocante aos recursos investidos para a GRS pelos municípios, em 2017, totalizaram cerca de R $\$ 28,5$ bilhões de reais no país (ALBREPE, 2017).

A região Nordeste representou cerca de 22,37\% dos resíduos coletados no país, em 2017, totalizando 43.871 toneladas. Demonstrando a enorme representatividade da região em relação a coleta de RSU, visto que, ultrapassa todas as outras regiões do país, com exceção da região sudeste, que totalizou 52,9\% dos RSU coletados, ou seja, 103.741 toneladas (ALBREPE, 2017).

O país tem buscado agir em busca da eficiência nesse tipo de gestão, através da criação da Política Nacional de Resíduos Sólidos (PNRS), instituída pela Lei no 12.305 de 2010, que destaca-se no cenário político internacional por propor ações desafiadoras para a gestão urbana, no que concerne a implementação de diretrizes relativas à gestão integrada, incluindo a responsabilização do setor público, do consumidor, do cidadão e do setor privado na adoção de estratégias que busquem minimizar os impactos negativos da geração de resíduos sólidos para o contexto socioambiental, além de estimular o uso de mecanismos econômicos sustentáveis (Rocha et al., 2017).

A PNRS traz à GRS no Brasil um contexto revolucionário, onde o pensamento social de que esta gestão é de exclusiva obrigação do governo, passa a dar espaço a uma conscientização social, onde os cidadãos compartilham dessa reponsabilidade, não se restringindo, apenas, ao pagamento dos impostos, mas atuando de forma efetiva com ações direcionadas à busca pela qualidade de vida social e pela manutenção do meio ambiente (Rocha et al., 2017).

Vale ressaltar os princípios adotados pela PNRS, o que possibilita entender melhor a estratégia utilizada pela mesma, sendo eles: a prevenção e precaução na produção de resíduos; a visão sistêmica necessária à gestão de RSU; a participação conjunta entre diversas esferas do poder público, empresarial e social; e por fim, a adoção de uma visão social que reconhece o resíduo sólido como um bem capaz de gerar valor econômico e social, através da possibilidade de reutilização e reciclagem do mesmo (Rocha et al., 2017).

A PNRS coloca em confronto ações, já comumente utilizadas pela sociedade e pelo poder público, em busca de uma sinergia entre todos os envolvidos. Por isso, é ilusório acreditar que a mesma não enfrente enormes desafios para sua implementação, podendo compreender um período de médio a longo prazo, o que depende de outras variáveis presentes no sistema (Rocha et al., 2017). 


\section{Mu e a análise dos fluxos de materiais (AFM)}

As cidades são conceituadas como "organismos que consomem recursos de seus arredores e excretam resíduos. As cidades transformam matérias-primas, combustível e água para o ambiente construído, biomassa humana e resíduos” (Decker, et al., 2000). Dentre as abordagens da gestão socioambiental, a corrente do MU defende que os sistemas urbanos, analogamente aos naturais, apresentariam um metabolismo (Kuhn, et al., 2017), conceituando-se MU como "a quantificação das características metabólicas de áreas urbanas, a partir da troca de recursos entre uma unidade urbana em particular e suas regiões de suporte" (Wolman, 1965).

O referido termo, ainda pode ser definido como, "a soma total dos processos técnicos e socioeconômicos que ocorrem nas cidades, resultando em crescimento, produção de energia e eliminação de resíduos" (Kennedy et al., 2007). Para Deilmann (2009), a abordagem do MU pode ser debatida a partir da perspectiva do consumo de recursos e geração de resíduos, inerentes às características de cada cidade.

Os estudos sobre conceito de MU tiveram início com o trabalho de Wolfman, em 1965. Em sua pesquisa, o autor teve como objetivo quantificar os fluxos de entrada e saída sobre o uso de diversos recursos como, água, combustíveis e alimentos, resíduos sólidos e gasosos em uma cidade americana hipotética de um milhão de pessoas (White, 2002). Os trabalhos que sucederam o estudo de Wolfman foram desenvolvidos em três cidades reais, sendo elas: Tóquio (Hanya \& Ambe, 1976), Bruxelas (Duvigneaud \& Denayeyer-de Smet, 1977) e Hong Kong (Newcombe et al., 1978), tendo como característica principal a abordagem interdisciplinar, resultante do diferente perfil profissional dos pesquisadores, sendo eles, respectivamente, engenheiros químicos, ecologistas e engenheiros civis.

Segundo Álvarez (2014), como resultado de pesquisas realizadas por vários autores, nos anos 90 aos anos 2000, podese concluir que o MU possibilita a existência simultânea dos elementos naturais das cidades, com os indivíduos que as habitam, produzindo valores econômicos e sociais, através das atividades de sustento presentes nesse ecossistema. Ademais, o MU é responsável por identificar as demandas de recursos naturais e a quantificação de resíduos descartados nos sistemas naturais das cidades, contribuindo, de forma efetiva, para a gestão ambiental.

Chen e Chen (2015) defendem que as cidades modificam a organização social de energia e materiais com as suas intensas atividades de consumo e produção. Desse modo, a sustentabilidade do sistema deve estar em constante processo de aperfeiçoamento e adaptação, no qual o conceito de MU atua como uma ferramenta importante na busca por eficiência metabólica no sistema urbano (Chen \& Chen, 2015).

O MU de uma cidade pode ser estudado através de diversas abordagens e metodologias. A Análise dos Fluxos de Materiais (AFM) tem como objetivo quantificar os fluxos de materiais e energia em uma cidade, focando, principalmente, nos materiais, visto que apresentam uma característica decisória para a sustentabilidade dos sistemas urbanos (Brunner, 2007).

Daniels e Moore (2001) consideram a AFM "uma abordagem, visto que, sem ser associada a procedimentos específicos, se apresenta como uma estrutura aberta a um escopo e aplicação genérico" (Khun, 2014, p.49). Para ConAccount, projeto fundado pela Comissão Europeia, entre 1996 e 1997, com o intuito de estudar o MU, incluindo os segmentos empresa e sociedade, em diversos níveis, a AFM atua como uma cobertura a diversas abordagens, já que, dispõe de múltiplas metodologias e meios de investigação (Khun, 2014).

Segundo Obernosterer et.al., (1998) a AFM atua examinando os fluxos de matérias e estoques dentro de um sistema, seja ele, local e isolado ou amplo e complexo. Além disso, avalia o resultado desses fluxos em relação a outros sistemas. Desse modo, demonstra sua importante utilidade para avaliar as inter-relações entre as cidades e seus entornos. Niza e Ferrão (2009) defendem que a análise estatística dos fluxos de materiais de um sistema não implica, somente, na avaliação de inputs e outpus, já processados, mas contribui para a estimativa das tendências de consumo desse sistema, e por isso, deve ser considerado um método de desagregação de dados eficiente para a dinâmica do MU. 
A AFM, no contexto das cidades, é composta por duas vertentes principais: (1) Análise dos Fluxos Totais de Materiais (AFMT), responsável por quantificar os fluxos mais amplos presentes no sistema; e (2) Análise dos Fluxos de Substâncias (AFS'), que atua, na quantificação dos fluxos de substâncias específicas dentro das fronteiras do sistema em estudo (Binder, Van der voet \& Rosselot, 2009).

Contudo, Ribeiro et al., (2007) afirma que os materiais depositados no ambiente podem se tornar um recurso de grande importância para a cidade, bem como, não sendo manipulado de forma eficiente, torna-se um poluente em larga escala, resultante do estoque formado pela humanidade.

\section{Resultados}

\subsection{Práticas de gestão de resíduos sólidos}

As práticas de GRS têm sofrido mudanças estratégicas a fim de solucionar ou reduzir os problemas ambientais causados pelo aumento da produção de resíduos e seu contínuo acúmulo desordenado (Demajorovic, 1995). Diante dessa perspectiva teórica, verificou-se as seguintes práticas de GRS atuantes no município G, através do relato de G2:

Nós temos várias práticas de gestão que envolvem, varrição, coleta domiciliar, coleta industrial, coleta de construção civil. Tem esse manuseio que vai ser feito, tem o depósito no aterro sanitário, os cuidados com as calhas, armazenamento onde já encontramos solo morto. Nós temos correção de solo, muita coisa, apagar muito incêndio... A gente tá fazendo manutenção através de uma empresa pra fazer os canais de drenagem, destinação de chorume, $e$ uma chaminé de escape... Existem outros projetos pra aproveitar o manuseio do aterro, geração de energia, de substâncias que possam servir de adubo orgânico. Existe também, no nosso aterro, uma cooperativa de catadores de reciclagem, que nunca funcionou, mas que tá sendo revitalizada agora. A proposta nova que a gente tem é que a gente vai fazer uma reunião com eles pra gente poder fazer essa classificação a nível industrial (G2).

Em relação às práticas de GRS utilizadas na cidade X, G1 enfatizou as diversas dificuldades financeiras e sóciopolíticas enfrentadas para o desenvolvimento de novas estratégias, demonstrando algumas deficiências não expostas na fala de G2, no que diz respeito à exposição de problemas enfrentados nesse tipo de gestão:

Hoje a gente se limita basicamente a tentar organizar uma infraestrutura e uma logística de coleta de resíduos e disposição final. Essa coleta, o máximo que a gente consegue oferecer à comunidade, infelizmente, é um período. Por exemplo, a coleta é periódica, que são determinados dias específicos. Mas a gente só consegue oferecer pela manhã ou à tarde, a gente não consegue oferecer na precisão de um horário, por exemplo de 10h às $11 \mathrm{~h}$. Por que essa informação é importante? Porque quando a gente não oferece isso para a comunidade, infelizmente, pela situação social do Brasil e por outros elementos, você tem a figura do agente ambiental, normalmente conhecido como catador, e quando ele não tá incorporado à coleta, muitas vezes eles acabam pegando esse material, eles rasgam e se espalha, isso dificulta demais a coleta. O que a gente chama de combo de frota, que são o caminhão, o motorista e os coletores, então eles têm que parar e coletar esse material, de forma menos eficiente, então isso é uma dificuldade. Outra dificuldade também é a questão dos próprios equipamentos. Dentro do que o município gasta, coleta de resíduos sólidos é uma das coisas mais caras que tem. Provavelmente, perde para educação, saúde... Então, essa logística tão cara faz com que você não tenha, por exemplo, caminhões novos, você tem muitos gastos com manutenção de veículo... Está havendo uma municipalização de demandas do governo federal, do governo estadual que estão passando cada vez mais obrigações para os municípios, hoje não está havendo mais os repasses de custeio na mesma proporção. Os municípios são responsáveis por educação básica, segurança, coleta de resíduos, saúde, sendo que os repasses não se alteram, então fica muito comprometido o orçamento... É verdade que quem atua na área, se vê sozinho nessa batalha. A sociedade vê só uma parte da problemática, mas a problemática é mais profunda (G1).

Desse modo, G1 fala dos fatores "custo" e prioridades sócio-políticas relacionados às dificuldades de atuar com práticas de gestão de resíduos mais eficazes e restringe essas práticas à aquisição e manutenção de materiais, como caminhões de lixos. Em contrapartida, G2 demonstra, através da sua fala, a evolução dessas práticas de GRS, com ênfase além da coleta de resíduos e disposição final, citando também o tratamento dos solos, o aproveitamento energético e a intenção do 
envolvimento popular, principalmente em relação à iniciativa da organização dos catadores de lixo nesse processo de busca pela eficiência da GRS.

Nota-se, ainda, que a fala de G2 demonstra que as práticas de gestão de resíduos utilizadas na cidade metropolitana X corroboram a visão de Demajorovic (1995, p.90), que defende o "ecological cycle management", já citado. Por outro lado, percebe-se que a fala de G1 expõe alguns aspectos referentes à deficiência gerencial e institucional de muitos municípios brasileiros, no que concerne às diretrizes estratégicas contidas na PNRS (Heber \& Silva, 2014).

A respeito das estratégicas de GRS desenvolvidas no município P, pôde-se verificar, através da fala de P1 e P2 que a secretaria responsável no município por essa gestão, atua em parceria com o Instituto do Meio Ambiente - IMAC, localizado nas dependências físicas da Secretaria de Patrimônio, Serviços Públicos e Transporte. É notória a extrema importância dessa parceria, através do relato enfático dos entrevistados, para o desenvolvimento das atividades relacionadas à GRS do município:

(...) o IMAC nos ajuda muito com a questão da educação ambiental e também com a coleta seletiva, através duma empresa né, uma cooperativa que eles tem lá, de catadores, que eles são inscritos, regulamentados, e algum, alguns locais privados principalmente, mas também tem algumas escolas, enfim, eles vão montando parcerias entre algumas empresas, algumas escolas, onde esses catadores vão sempre lá recolher seu material reciclável né. Outra parceria que o IMAC tem com a gente é a recuperação de áreas degradáveis, é, atualmente o, o município conta com 110 áreas órfãs, ou seja, áreas órfãs são aquelas áreas que a gente sabe que tem alguém que coloca resíduos sólidos, mas a gente não consegue identificar quem é essa pessoa. Então, algumas vezes, com a ajuda da comunidade e com essa parceria com o IMAC, a gente vai e revitaliza essa área, ou urbanizando, criando uma areninha, uma praça, colocando algo do tipo pra benefício da comunidade ou então criando aquela, aquela, jardim com pneus, com material reciclável né, a gente utiliza, a gente vai tentando, é, amenizar essas áreas órfãs (P2).

Os relatos mencionados acima corroboram com as diretrizes da PNRS que defendem a responsabilização mútua entre governo e sociedade a respeito de assuntos relacionados à GRS, não se restringindo, apenas, ao pagamento de impostos pela comunidade, mas dando espaço a uma conscientização social, onde os cidadãos compartilham soluções para essa problemática (Rocha et al., 2017).

Em contrapartida, os entrevistados relataram que as estratégias de GRS, atualmente, estão bastante restritas ao serviço de coleta e disposição final dos resíduos, e isso deve-se ao alto nível de complexidade desses serviços, como descrito abaixo por P2:

(...) então a gente conta aqui com caminhão compactador, com caçamba e a gente vai até quando, de acordo com, o tanto de produção daquela comunidade, o tanto que, é, a questão das estradas mesmo, a questão do acesso, a questão da própria cultura daquela comunidade, ela produz mais o quê, é questão de poda, é questão de lixo domiciliar, é uma área que a gente percebe que tem muita construção, que tá crescendo muito, e gera muito entulho, então a gente procura conhecer, identificar quais são as principais necessidades de cada área dessa e ai a gente divide "o município P", no nosso mapa aqui de coordenação, em seis regiões; a "região X" a gente dividiu em duas áreas, porque realmente é uma das maiores produtoras de resíduos sólidos por conta do tamanho da população que lá vive; a gente dividiu a faixa litorânea toda, como outra região porque é muito extensa, a gente tem também a área da sede, que a gente considera centro, os principais bairros ao redor; a gente tem também a questão do sertão e da serra; então a gente dividiu o grande município nessas áreas e aí a gente todos os dias, a gente programa atender qual bairro a gente vai, claro, já tem os caminhões que já tem as suas rotas fixas que a gente nunca muda... (P2).

A respeito do processo de tratamento dos resíduos, o sujeito P2 relata novamente a parceria com o IMAC para a realização da reciclagem de materiais, além disso descreve a reutilização de materiais para a manutenção do espaço público do município:

(...) o entulho, a gente, no momento a gente reutiliza, por exemplo, quando a população precisa aterrar alguma coisa, a gente precisa tampar um buraco, então a gente reutiliza o entulho, nesse sentido de benefício da população, porque tem uma questão que a gente precisa realizar, não tem sentido a gente comprar aterro, se a gente tem geração diante todo município, e mais, a questão do resíduo domiciliar mesmo, aquele resíduo digamos assim, que é considerado 
lixo, a gente realmente destina ao $Y$, que é o aterro sanitário que está instalado aqui em $P$, é um consórcio entre A e $P$, então esses dois municípios, eles podem tá destinando seus resíduos pra lá (P2).

No que se refere à administração do aterro sanitário da cidade, foi possível identificar a atuação de uma empresa terceirizada para a administração do mesmo. Na fala de P1 é citada a parceria entre a empresa "B" e o município: "Aqui dentro do município "P", ali na BR, tem um aterro sanitário, que por sinal, é gerenciado pelo grupo B né, onde, todos os resíduos sólidos do município P e A ... são despejados lá" (P1). Na sequência, P2 descreve essa parceria em detalhes:

(..) temos a fiscalização da prefeitura lá, em nosso território, então a gente tem tanto, o dever quanto o direito de tá lá dentro fiscalizando e também tem a administração de uma empresa particular, no caso é o grupo B e da prefeitura de A, então esses três... ficam na questão da coordenação do aterro (P2).

Diante dos relatos expostos de P1 e P2, é possível perceber a complexidade dos fatores envolvidos no processo de GRS do município, onde a extensa concentração populacional atua como uma variável dificultadora do processo, além da necessidade de maiores investimentos urbanos e sociais.

Os resultados provenientes das falas dos gestores dos dois municípios corroboram com a afirmação de Bruce (1995) que enfatiza a necessidade de cooperação de vários fatores para a efetiva realização das etapas do sistema, entre eles: um extenso período de investimentos em infraestrutura urbana e um elevado nível de instrução social, responsável pelo estímulo de participação da população nas políticas utilizadas por esse tipo de gestão.

\subsection{Percepção dos servidores sobre o conceito de metabolismo urbano}

Nesta pesquisa, buscou-se identificar a percepção dos servidores públicos a respeito do conceito de MU. O conhecimento desse conceito pode direcionar a gestão dos sistemas urbanos na obtenção de maior eficiência metabólica (Galvão et al., 2017). Nesse contexto, foi possível identificar, através da fala dos entrevistados G1 e G2, trechos referentes à associação do metabolismo de uma cidade com o metabolismo celular. G2 faz uma referência aos fatores de consumo de recursos, geração de capitais e responsabilidades sociais contidos nesse metabolismo, como exposto:

[ENTREVISTADO OLHANDO PARA FOTO DISSE]: Nós temos um conflito ordenado e um consumo que não tem pé nem cabeça. [NESSA FOTO]: Então assim, temos uma cidade que apresenta dois tipos de desenvolvimento orgânico: Um está ordenado e o outro desordenado. A nível celular seria a respiração das mitocôndrias, se você tem uma boa oxigenação, embora o oxigênio não vá pro corpo, você tem uma parte que é aproveitada plenamente, caso contrário não se tem esse aproveitamento pleno. Nós temos, aqui, uma parte que está ordenadamente consumindo e cuidando da proliferação da cidade e outra que está só acumulando. O mesmo jeito é a cidade, eu tenho um que consome bem, geram bons resíduos e tenho o que não faz digestão, é a cidade metabolicamente falando. Então excelente metabolismo, excelente digestão, excelente inspiração à nível celular, é o que necessitamos na situação que a gente tá (G2).

G1 enfatizou o desconhecimento prévio da expressão lida (MU), mas expôs aspectos relacionados diretamente ao consumo de recursos das cidades, no que diz respeito aos problemas atualmente vividos pelas mesmas, por meio de uma metáfora relacionada ao desequilíbrio do sistema urbano como um todo.

[ENTREVISTADO OLHANDO PARA A EXPRESSÃO] Essa expressão é especificamente nova pra mim. Apesar de eu já ter um tempo trabalhando na área de meio ambiente, ela é nova. Mas se pegarmos os componentes dela, por exemplo, pra mim, metabolismo seria as reações que permitem que os organismos se desenvolvam, produzindo e consumindo, catabolisando e anabolisando no sistema urbano, então a ideia seria que todos os elementos sejam de operação, de logística, de construção, de desenvolvimento do ambiente urbano, a interação deles pra construção do espaço urbano. A gente vê que está havendo uma desproporção na qualidade desse metabolismo, a gente vê que uma parte da cidade tem acesso aos melhores nutrientes, enquanto a outra renegada, as sobras. Porém, a gente vê que, no geral, todo corpo fica doente, porque se uma parte tá comprometida, o inteiro vai ser comprometido (G1). 
Nesse contexto, foi possível identificar percepções diferentes a respeito do conceito de MU. Porém, essas percepções concordam, entre si, através das falas de G1 e G2, sobre o entendimento do aspecto cíclico da expressão MU em relação ao sistema urbano, com a finalidade de aumentar a eficiência da gestão desse sistema como um todo. Tais entrevistas ratificam esse conceito no que concerne à análise da cidade como um organismo vivo, onde os fluxos de entrada e saída de materiais e energia nas cidades são sistemáticos e a compreensão desses fluxos é essencial às mesmas (Galvão, Marinho \& Miranda, 2017).

Quando considerada as percepções dos entrevistados P1 e P2, é necessário enfatizar o contínuo desconhecimento dos mesmos em relação à expressão "MU", apresentada como elemento estímulo durante a entrevista. Desse modo, P1 faz referência ao movimento contínuo da cidade, como exposto abaixo:

[ENTREVISTADO OLHANDO PARA A EXPRESSÃO] Seria o desenvolvimento é (...) o funcionamento, o desenvolvimento de toda a cidade, o desenvolvimento de resíduos, o movimento de um desenvolvimento urbano, né?! Vendo por esse lado, o metabolismo de uma coisa que funciona, entendeu, uma máquina funcionando em função do urbanismo, digamos assim (P1).

Diante desse relato, P1 apresenta uma compreensão superficial a respeito da expressão. Vale ressaltar, ainda, que foi apresentada a foto referente ao contexto de MU (Apêndice A) como um outro elemento estímulo ao entrevistado, que manteve o discurso acima. Na visão de P2, a expressão MU remete às características específicas do funcionamento da cidade, enfatizando a relação entre a velocidade das trocas e fluxos dos processos na mesma:

[ENTREVISTADO OLHANDO PARA A EXPRESSÃO] Bem, urbanização ao que eu entendo, é a modificação de uma paisagem que seria natural e o metabolismo, trazendo aqui pro corpo humano né, ele pode ser mais acelerado, mais lento, então $M U$, eu acho que, tem mais a ver com isso, alguma coisa relacionada a urbanização de ser mais lenta ou mais rápida em alguma área, o que me vem na cabeça é isso (P2).

Diante do exposto, pôde-se perceber que a visão dos gestores do município P diferem, entre si, onde para P1 a expressão MU resume-se ao desenvolvimento da malha urbana, já pela ótica de P2, a mesma apresenta uma característica intrínseca relacionada ao funcionamento do metabolismo humano, corroborando com as visões expostas por G1 e G2.

Diante das análises de conteúdo expostas, percebe-se a convergência nas falas da maioria dos entrevistados com a literatura de MU, no que concerne a compreensão intelectual da metáfora, isto é, a relação entre o conceito de MU e a definição de metabolismo humano, caracterizado pela declaração de que os sistemas urbanos, em equivalência aos sistemas naturais, apresentariam um metabolismo (Kuhn, Sattler \& Magnus, 2017). No entanto, é necessário observar que todos os entrevistados demonstraram desconhecimento prévio a respeito do conceito de MU em suas práticas profissionais como gestores, ou seja, nenhum deles, em suas carreiras profissionais ligadas à gestão pública tinham conhecimento técnico referente à expressão apresentada.

\subsection{Relação entre percepção de metabolismo urbano e práticas de gestão de resíduos sólidos}

Nesta seção realiza-se uma análise referente ao conceito de MU, identificado através das falas dos entrevistados na seção anterior, e descrito, nesta pesquisa, por meio de autores referenciados na bibliografia, em relação às práticas de GRS atuantes nas cidades metropolitanas $\mathrm{G}$ e P.

De acordo com a fala de G2, foi possível analisar expressões que denotaram extrema importância, no que diz respeito à adoção de uma visão sistemática na GRS. Notou-se também, a dificuldade de atuação dessa visão, hoje, que para o gestor entrevistado ainda é comumente tratar como algo utópico, porém, para ele o surgimento de uma nova visão remete a grande importância: 
Eu acho que devia ser simbiótica. Se você tiver uma simbiose, biologicamente falando, um necessita do outro. $O$ resíduo sólido é necessário? É, porque eu só desenvolvo a cidade se eu tiver trabalho... A cidade quando faz uma pavimentação, gera também resíduos. Um hospital gera resíduos, um jardim gera resíduos, um animal gera resíduos. A junção desse amontoado de resíduos, diz respeito a como a cidade gira e como a cidade vive. E isso diz respeito muito há como você administra esse resíduo sólido, como você faz a manutenção do seu aterro sanitário, como você faz a classificação do que você tá colhendo e, principalmente, como você interage com os habitantes. $O$ pessoal diz assim: isso é muito utópico, isso é muito filosófico. Você pode mudar alguma coisa através de uma filosofia nova $(G 2)$.

No entanto, G2 também cita um estudo, que está em andamento na cidade metropolitana X, referente à futura implementação de um projeto de GRS, já atuante em alguns países desenvolvidos. Tal projeto, segundo o mesmo, visa o máximo aproveitamento dos insumos e da energia, proveniente dos resíduos, através da implantação de um sistema de tratamento e gestão que envolve, de forma direta, a participação popular e a geração de recursos financeiros. Essa informação pode ser identificada nos trechos abaixo:

Tem essa divisão, são três etapas lá: classificação da coleta, a bustão de resíduos para geração de adubo, solo pra agricultura e a outra parte é a geração de energia, resultado da combustão... Esse projeto a gente teve gestores aqui da região metropolitana, que foram de SP até Campinas, para conhecer o projeto e o protótipo. Conhecemos a fábrica de equipamentos, todo o sistema produtivo, estudamos pra ver se é auxílio e o que custava para auxiliar a parte social né, os catadores, que são 63 empregos diretos, quando o projeto for implantado... O protótipo está em Montimor. Essa é uma ideia nova que a gente tá tentando trazer. Então essa parte aí de gestão, principalmente esse gerenciamento de reciclagem gera pra comunidade um bem estupendo. Se você pegar uma derivação de não gasto em matéria prima e não prejuízo pro meio ambiente, que não vai te causar doenças na comunidade, que não vai te causar entraves no saneamento básico, quanto é que a população, quanto é que o governo municipal e até o federal tá economizando em dinheiro? Essa é a mentalidade que o prefeito tem pra implantar e a gente já ver várias cidades no exterior fazendo esse tipo de coisa. Nós temos em Londres, Paris, a própria China tem. Então são ideias (G2).

No que se refere à fala de G1, demonstrou-se de forma superficial a relação percebida por ele, entre a GRS e o conceito de MU. Enfatizando que hoje essa relação apresenta um caráter deficiente:

Quando a gente fala de resíduos sólidos, a ideia de metabolismo, a gente pode imaginar a questão da qualidade dos rejeitos que são produzidos. No metabolismo é formado rejeitos, fezes, suor, e quando a gente fala de resíduos sólidos, é onde tem exatamente isso. Os indivíduos produzem resíduos e a gente tem que excretá-los. E hoje no Brasil, não só na cidade $x$, a gente tem muita dificuldade na disposição desses rejeitos, a gente não consegue metabolizar o tanto com qualidade, que no caso seria a reciclagem desses nutrientes. Pode-se reciclar hoje, há técnicas fáceis de reciclar papel, vidro, plástico, metais em geral, e em construção civil, que isso a gente não faz porque existem nutrientes que são perdidos. E desses nutrientes que são perdidos juntos com outros que não podemos, até material orgânico poderia ser, a gente tem soluções como compostagem. Tudo isso poderia não ser lançado no ambiente, não precisaria ser excretado, mas infelizmente ocorrendo a excreta dele, a dificuldade de correr atrás da escolha certa, aí você vê o lançamento deles, a construção de lixões. Então essa é uma relação de metabolismo e resíduos sólidos (Gl).

Em relação aos relatos dos entrevistados do município "P”, verificou-se a partir da fala do sujeito P1 uma contrariedade de percepção com a real influência do conceito de MU, registrado na literatura. Para esse sujeito, a relação entre as práticas de GRS utilizadas na cidade e o conceito de metabolismo se resume a atuação social, onde o mesmo responsabiliza o contexto social pelas deficiências presentes na GRS, como exposto abaixo:

O conceito que eu tenho, é que enquanto o ser humano não se conscientizar e puder ajudar ao meio ambiente, ao próximo e a si mesmo, não vai mudar. Eu tenho exemplo aqui no nosso município, a gente limpa, aqui agora, com meia hora depois, talvez não vá nem tudo isso, às vezes, com dez minutos que o carro tá passando, a gente tá vendo, um carro ali na frente da gente, a pessoa tá jogando lixo. Enquanto não se conscientizar, pode ter certeza que a coisa não vai funcionar. (P1)

Em contrapartida, o sujeito P2 faz referência à relevância das necessidades particulares do município para a 
elaboração de estratégias de GRS. Desse modo, demonstra de forma detalhada o seu entendimento a respeito das práticas de GRS utilizadas na cidade e o conceito de MU, antes relatado.

Eu acho que eu vou acabar voltando um porquinho pra aquela questão que eu disse que a gente dividiu "o município $P$ " de acordo com o que a gente percebeu de necessidade no município né, porque assim, o, resíduo solido, ele tá muito interligado também a economia... A gente percebe no resíduo solido, até mesmo porque, por exemplo, numa área que ela é mais urbanizada, que tem um poder aquisitivo mais elevado, você percebe um tipo de resíduo diferenciado do que numa área que não é tão urbanizada, onde você percebe mais resto de comida orgânica, referentes ao consumo básico porque essas pessoas só tem dinheiro pra comprar essas coisas, enfim, a sua comida, então o MU, ele tá muito gerado assim, com a questão da economia que tá vinculada com a questão de produção de resíduo sólido, tanto de gerar mais, quanto, que tipo de resíduo vai tá sendo gerado. Então, é, eu acho que, é uma estratégia que o nosso município tá usando, mas que poderia servir de exemplo pra outros municípios, você enxergar o seu município com as particularidades dele e não a questão de uma coleta só, a fim de executar um serviço de qualquer maneira, é isso que a gente tem feito aqui, tem tentado fazer, porque a gente sabe que a gente tem muita coisa pra melhorar, enfim, muita coisa pra adequar, mas a gente tem tentado enxergar "o município P" com as particularidades dele e não tentar fazer a coleta de uma forma só, a fim de executar o serviço. (P2)

Diante do relato anterior, o sujeito enfatiza, por diversas vezes, a ligação da GRS com a economia do município, exemplificando que as características socioeconômicas influenciam na quantidade e no tipo de resíduo gerado pela população. Tal afirmação corrobora com a abordagem da literatura do conceito de MU baseado no contexto em que a economia atua como um subsistema ambiental, onde o fluxo de materiais e energias determinam as relações existentes entre os dois componentes desse sistema, a economia e o meio ambiente (Daly, 1996). É válido colocar em evidência que todos os entrevistados não relacionaram a GRS de seus municípios à necessidade de quantificação dos fluxos de materiais e energias provenientes do funcionamento da cidade. Destacando em suas falas, somente, a ação popular e a avaliação das particularidades dos municípios. Nesse aspecto, apenas dois dos entrevistados relacionaram de forma direta o desenvolvimento econômico do município ao máximo aproveitamento desses resíduos e ao surgimento de uma nova visão sistêmica a respeito das estratégias de tratamento e disposição dos mesmos.

Conclui-se que não há um alinhamento das práticas de GRS com o conceito de MU, nas cidades estudadas. Tal afirmação é referenciada pela quase ausência total de estratégias relacionadas ao estudo aprofundado dos fluxos de materiais e energia provenientes do município. Desse modo, não houve identificação de metodologias, como a Análise do Fluxo de Materiais - AFM, validada pela corrente teórica do MU, que defende a atuação da AFM no estudo dos fluxos de matérias e estoques dentro de um sistema, seja ele, local e isolado ou amplo e complexo, colaborando, também, para o resultado dos fluxos em relação a outros sistemas (Niza, Rosado \& Ferrão, 2009).

\section{Considerações Finais}

A pesquisa visou compreender qual a influência do conceito de MU nas estratégias de GRS atuantes em duas cidades da região metropolitana de uma capital do nordeste brasileiro.

O estudo caracterizou as práticas de GRS através das entrevistas realizadas e identificou que as estratégias atuantes nas secretarias estudadas se resumem, predominantemente, ao serviço de coleta e disposição final dos resíduos. Em contrapartida, foi notório o surgimento de novas ações que valorizam a gestão integrada das secretarias e buscam métodos de inovação no tratamento de resíduos, referenciadas por alguns gestores como manifestações importantes para adoção de uma nova visão a respeito da GRS no setor público e na sociedade.

A respeito da percepção dos servidores públicos sobre o conceito de MU, concluiu-se a ausência total do conhecimento prévio dos gestores a respeito do conceito de $\mathrm{MU}$, onde a maioria dos entrevistados relacionou o mesmo ao funcionamento do metabolismo humano, enfatizando que suas falas correspondiam a um "relato de conhecimento de mundo". 
A ausência do conhecimento técnico pode influenciar de forma significativa no não desenvolvimento de estratégias, com base nesse conceito. Destaca-se, contudo, que um gestor demonstrou uma pioneira ação na direção de sistematização da GRS, com base na integralização das regiões de suportes e na gestão adaptativa.

Sobre a análise da relação entre o conceito de MU e as práticas de GRS utilizadas percebeu-se, através das análises dos conteúdos provenientes das entrevistas, a relação mínima ou ausente entre as práticas de GRS utilizadas nos municípios estudados e o conceito de MU nas estratégias utilizadas para a GRS nas cidades G e P, não sendo possível identificar a presença de metodologias validadas pelo conceito em questão.

A pesquisa visou contribuir para a gestão socioambiental das cidades, no que concerne ao gerenciamento de resíduos sólidos, a fim de que as políticas públicas visem à estabilização do volume final de resíduos a serem dispostos em longo prazo, estimulados pela busca de um sistema de GRS eficiente, baseado no conceito de MU. Além disso, buscou contribuir com a literatura, no tocante ao conceito de MU aplicado à gestão socioambiental, já que existem poucas pesquisas brasileiras na área.

As limitações da pesquisa referem-se à realização de poucas entrevistas, justificadas pelo baixo número de gestores públicos responsáveis pela GRS nas cidades metropolitanas pesquisadas, agravado pela atuação no campo de estudo abrangendo apenas duas cidades da região metropolitana. Desse modo, sugere-se a ampliação do campo de estudo, com a finalidade de aprofundar a pesquisa.

Para estudos futuros, é importante desenvolver um panorama das estratégias utilizadas para a GRS de cidades metropolitanas do estado do Ceará com o intuito de comparar a evolução temporal dessa gestão, considerando os aspectos evolutivos das tecnologias e das práticas de sustentabilidade nos municípios. Assim, é importante o desenvolvimento de estudos futuros que visem propor um framework teórico abordando as práticas de GRS e a evolução destas nas regiões metropolitanas, com o objetivo de associar a existência dessas práticas com os fatores socioculturais das regiões e os recursos tecnológicos disponíveis na sociedade.

\section{Referências}

ABRELPE. (2016). Panorama dos Resíduos Sólidos no Brasil 2016. ABRELPE - Associação Brasileira das Empresas de Limpeza Pública e Resíduos Especiais

Andrade, R. M. D. \& Ferreira, J. A. (2011). A gestão de resíduos sólidos urbanos no Brasil frente às questões da globalização. Rede: Revista Eletrônica do Prodema, 6(1), 7-22.

Brasil (2010). Lei $\mathrm{n}^{\circ}$ 12.305, de 02 de agosto de 2010. Institui a Política Nacional de Resíduos Sólidos (PNRS). http://www.planalto.gov.br/ccivil_03/_ato2007-2010/2010/lei/112305.htm.

Bruce, J. (1995). Urban waste management: past, present and future perspectives. In: ISWA (ed.) International Directory of Solid Waste Management -tThe ISWA Yearbook. James \& James Science Publishers.

Brunner, Paul (2007). H. Reshaping urban metabolism. Journal of Industrial Ecology, 11(2), 11-13.

Castro, B. A., Araújo \& M. A. D. (2004). Gestão dos resíduos sólidos sob a ótica da Agenda 21: um estudo de caso em uma cidade nordestina. Revista de Administração Pública, 38(4), 561-588.

Chen, S. \& Chen, B. (2005). Sustainable Urban Metabolism. ResearchGate.

Daly, H. E. (1996). Beyond growth: The economics of sustainable development. Beacon Press.

Decker, E. H., Elliott, S., Smith, F. A., Blake, D. R. \& Rowland, F. S. (2000). Energy and material flow through the urban ecosystem. Annual review of energy and the environment, 25(1), 685-740.

Demajorovic, J. (1995). Da política tradicional de tratamento do lixo à política de gestão de resíduos sólidos as novas prioridades. Revista de Administração de Empresas - RAE, 35(3), 88-93.

Duvigneaud, P., Denayeyer-de smet, S. (1977). L'Ecosystéme Urbs, in L'Ecosystéme Urbain Bruxellois, in Productivité en Belgique. In: Duvigneaud, P., Kestemont, P. (Eds.), Traveaux de la Section Belge du Programme Biologique International, Bruxelles, 581-597.

Galvão, C. D. O., Marinho, S. D. A. M \& Miranda, L. I. B. (2017). Metabolismo urbano como ferramenta de suporte à gestão da água nas cidades. Encontro Nacional de Rede Observatório das Metrópoles. Natal. 
Research, Society and Development, v. 11, n. 2, e18311213428, 2022

Hanya, T. \& Ambe, Y. (1976). A study on the metabolism of cities. In: Science for Better Environment Proceedings of the International Congress on the Human Environment (HESC) Kyoto. HESC: Tokyo, Japan, 228-233.

Heber, F. \& Silva, E. M. (2014). Institucionalização da política nacional de resíduos sólidos: Dilemas e constrangimentos na região metropolitana de Aracaju (SE). Revista de Administração Pública, 48 (4) 913-937.

IBGE. Instituto Brasileiro de Geografia e Estatística. (2010). Censo Demográfico. www.ibge.gov.br.

IBAM. Instituto Brasileiro de Administração Municipal. (2001). Manual de Gerenciamento Integrado de Resíduos Sólidos. http://www.resol.com.br/cartilha4/manual.pdf

Kennedy, C., Cuddihy, J. \& Engel-yan, J. (2007). The changing metabolism of cities. Journal of industrial ecology, 11(2) 43-59.

Kuhn, E. A., Sattler, M. A. \& Magnus, L. D.; Contribuições do conceito e da abordagem de metabolismo urbano para a avaliação do custo das decisões ambientais. Revista Thésis.

Maiello, Antonella, Paiva B. \& Ana L. N., Valle, T. F. (2018). Implementação da Política Nacional de Resíduos Sólidos. Revista de Administração Pública, 52(1) 24-51.

Marconi, M. de A. \& Lakatos, E. M. (2010). Fundamentos de metodologia científica. Atlas.

Newcombe, K., Kalma, J. \& Aston, A., (1978). The metabolism of a city: the case of Hong Kong. Ambio 7(3).

Niza, S., Rosado, L. \& Ferrão, P. (2009). Urban Metabolism Methodological Advances in Urban Material Flow Accounting Based on the Lisbon Case Study. Journal of Industrial Ecology. Lisboa, Portugal, 13 (3) 384-405.

Obernosterer, R.P. B., Daxbeck H., Gagan T., Glenck E., Hendriks C., Morf L., Paumann R., \& Reiner I. (1998). Materials accounting as a tool for decision making in environmental policy: Mactempo case study report. Urban metabolism, the city of Vienna.

Pereira, A. S., Shitsuka, D. M., Parreira, F. B., \& Shitsuka, R. (2018). Metodologia da pesquisa científica [recurso eletrônico UFSM. https://repositorio. ufsm. br/bitstream/handle/1/15824/Lic_Computacao_MetodologiaPesquisa-Cientifica. pdf.

PNUD Brasil. Programa das nações unidas para o desenvolvimento no Brasil. (2016). Desenvolvimento Sustentável. http://www.br.undp.org.

Ribeiro, P., Niza S. \& Ferrão P. (2007) Material flow accounting and waste production forecasting: A tool for decision-making. Paper presented at the ISIE Conference, Toronto, Canada.

Rocha, S. M., Rocha, R. R. de C. \& Lustosa, K. B. (2017). Política brasileira de resíduos sólidos: reflexões sobre a geração de resíduos e sua gestão no município de Palmas-TO. Revista ESMAT, 9(13), 29-44. https://doi.org/10.34060/reesmat.v9i13.189.

Vergara, S. C. (2005). Métodos de pesquisa em administração. Atlas.

Wolman, A. (1965). The Metabolism of Cities. Scientific American, 213, 179-190. 